University of Nebraska - Lincoln

DigitalCommons@University of Nebraska - Lincoln

To Improve the Academy

Professional and Organizational Development Network in Higher Education

1994

College Students' Perceptions of Unfairness in the Classroom

Rita Cobb Rodabaugh

Follow this and additional works at: https://digitalcommons.unl.edu/podimproveacad

Part of the Higher Education Administration Commons

Cobb Rodabaugh, Rita, "College Students' Perceptions of Unfairness in the Classroom" (1994). To Improve the Academy. 319.

https://digitalcommons.unl.edu/podimproveacad/319

This Article is brought to you for free and open access by the Professional and Organizational Development Network in Higher Education at DigitalCommons@University of Nebraska - Lincoln. It has been accepted for inclusion in To Improve the Academy by an authorized administrator of DigitalCommons@University of Nebraska - Lincoln. 


\section{College Students' Perceptions of Unfairness in the Classroom}

\section{Rita Cobb Rodabaugh}

Florida International University

The importance of creating an atmosphere of fairness in the college classroom is discussed. Using psychological equity theory concepts of interactional and procedural fairness as the basis of study, a survey was conducted with 300 university students who were asked to rate the seriousness of 18 faculty misbehaviors. Misbehaviors related to interactional fairness (showing partiality to some students, using profanity and being angry or mean, embarrassing students in class) and misbehaviors related to procedural fairness (unfair in grading; changing policies during the semester; using unfair tests, trick questions) were considered by students to be much more serious than giving excessive work or giving dull, boring lectures. This paper gives a model for consideration of the relative importance of fairness in the college classroom and offers recommendations for faculty.

Universally, college students put high value on fair treatment in the classroom. College students from cultures as diverse as the United States and Sri Lanka, when asked to describe the traits of "good teachers,"employ terms which denote fairness: "democratic," "treated all equal," "favored nobody," and "gave no special preference"(Shaw, Partridge, \& Gorrell, 1990). For decades, although other criteria for evaluating effective instruction have changed, fairness has remained a major concern among college students (Odom, 1943). Today, fairness is one of the top ten criteria used by college students to assess good teaching (Meredith, 1983). 
There is evidence that negative consequences result when students perceive unfairness or a lack of equity in an educational setting. Lack of achievement by students is related to their negative ratings of fairness in the classroom (Bryson, 1974; Frey, 1976; Marsh \& Overall, 1980). When students perceive unfairness, they rate professors lower on other characteristics (Feldman, 1976), and when describing their "worst" teacher, students almost always use statements which indicate unfairness. Low perceived equity is even related to college student participation in vandalism on campus (DeMore, Fisher, \& Baron, 1988).

If the perception of unfairness is correlated with a wide range of negative outcomes, then faculty members and administrators should be aware of behaviors and practices which foster a sense of unfairness among students. If college students respond negatively to certain classroom experiences or practices, then the result often may be lower achievement or decreased satisfaction with the university. What types of classroom experiences and practices create negative responses in students? Some of these questions can be answered through equity research.

\section{Theoretical Framework}

Equity theory, proposed by J. Stacy Adams in 1965, established fairness as an area of study within the field of social psychology. Simply stated, Adams' theory proposes that people are motivated to establish equity in their lives so that outcomes are proportionate to inputs. People do this by comparing their individual inputs and outcomes in any given situation with the inputs and outcomes of others in similar situations. One basic premise of Adam's (1965) equity theory is the assumption that people are motivated to establish reciprocity according to each individual's perception of what is fair. These expectations for reciprocity and fairness are learned through socialization and vary according to culture, gender, age, and other sociocultural variables (Benton, 1971; Boldizar, Perry, \& Perry, 1988; Murphy-Berman, Berman, Singh, Pachauri, \& Kumar, 1984).

As might be expected, most of the early research applying equity and fairness theory was conducted in business and industry. Most 
people are concerned with equity and fairness on the job; people expect fair pay from their employers and are motivated to reestablish fairness when they perceive that it does not exist. Although not as widely studied, the desire for fairness in the classroom may be as prevalent as concerns for equity in employment. A common complaint heard from students - from kindergarten to graduate school-is that a teacher is "unfair." We might assume that these students, when they perceive unfairness, are also motivated to reestablish fairness.

\section{Equity, Equality, Need}

The need for equity - that is, achieving outcomes which are comparable to inputs - is not the only criterion for measuring fairness. Adams' early equity theory has been expanded to include other concepts which are important to people's ideas of fairness (Deutsch, 1975; Leventhal, 1980). Deutsch (1975) found that outcomes which emphasizes equity (contributions) is only one of three means used to determine just distributions. Depending upon the circumstances, people might also use equality or need as the dominant criterion for assessing outcomes. Whereas rules of equity consider input, rules of equality dictate that everyone receive an equal share, regardless of input; and rules of need give the most to those who are most deprived. When the major concern is for economic productivity, as in factory production line work, then equity will tend to be the dominant justice rule used. If one is concerned with maintaining and fostering social relations, then equality will be the primary rule. For instance, parents will usually spend equal amounts of money for each child's birthday, regardless of the contribution from each child. If the major concern is for personal development, as determined by the social services system of our country, then need will be the major criterion for distribution.

How much importance should a professor place on a student's contribution to the class when assigning grades? Two experiments conducted by the author (Rodabaugh \& Kravitz, 1994) assessed participant ratings of this practice. One experiment compared professors who graded equitably with those who graded equally and with those who graded according to need. Participants read descriptions of a professor who assigned grades for a group project according to one 
of three methods: equitably, according to each student's individual contribution; equally among members of the group, ignoring individual contribution to the group; or according to the needs of individual students, ignoring the contribution of the student. The results showed that the professor who assigned grades equitably (according to the individual contribution of each student) was rated significantly higher on fairness, caring shown to students, and likelihood of being chosen for a class than were professors who graded according to need. Professors who graded according to need were in turn rated significantly higher than those who assigned grades equally. These results were significant at the .001 level. In the second experiment, participants read descriptions of a student who contributed either highly or minimally to a class during the semester, but finally scored only one percentage point away from a needed grade at the end of the semester. The point was needed either to keep financial aid, to stay on the basketball team, or to graduate. The professor decided to give the needed point in all cases. The data on all five dependent variables (fairness, caring toward students, respect, liking, and likelihood of being chosen for a class) indicate strong student support for faculty who consider a student's contribution when assigning grades, regardless of the reason for the need.

\section{Outcome vs. Procedural Fairness}

Even though people are concerned with just distributions, Thibaut and Walker (1978) proposed that people are also greatly concerned with the procedures used to determine those distributions. People will usually accept the outcome of a decision if they feel that the procedures used to determine the outcome are fair. Part of this "fair process effect" is the opportunity to vocally express one's feelings and thoughts about the procedures used to determine the outcome (Folger, Rosenfield, Grove, \& Cochran, 1979). This opportunity, labeled "voice," has been shown to be a valid contributor to people's perceptions of fairness. If individuals are given the opportunity to express themselves during the procedures which determine outcomes, or to express their feelings about the outcomes, then they are more satisfied with the outcomes even when they know they cannot change the results. 
Procedural fairness includes a number of components which might be considered necessary in order to assure fair processes (Levanthal, 1980), including agent selection, ground rules, information gathering, decision structure, appeals, safeguards, and change mechanisms. People expect the rules and procedures to have some degree of consistency, accuracy, and ethicality; to be free of bias; to be representative of the population; and to have built-in measures for correcting mistakes (Leventhal, 1976, 1980).

Three experiments (Rodabaugh \& Kravitz, in press) were conducted to assess college student perceptions of professors who use either fair or unfair procedures. The first study dealt with a professor's procedures related to testing, the second dealt with a professor's procedures related to classroom rules and policies, and the third compared a professor who was unfair to those who displayed other negative characteristics.

In the first experiment, a professor was either fair (returned tests to students, discussed the tests, and let students ask questions about the tests) or unfair (simply posted grades for tests) in the procedures followed when returning tests to students. The professor's grades in the class were higher than average, average, or lower than average. Ratings of the professor not only on "fairness," but also on the other four dependent variables (caring toward students, respect, liking, and likelihood of being chosen for a class), were strongly affected by the professor's fairness. Even when the professor's grades were lower than average, the ratings of the professor's fairness were significantly higher ( .001 level) than the ratings of a professor who showed unfairness, even if the grades for the unfair professor were higher than average.

The second experiment described a professor who was either very strict (fair) or negligent (unfair) in setting classroom policies and procedures and who awarded student grades which were either higher or lower than average. In this experiment, students rated a professor who was fair much more highly than one who was unfair on all five dependent variables. The same results were found as those described above: a professor using fair procedures and awarding low grades was rated significantly higher than a professor using unfair procedures and awarding high grades (.001 level). 
In the third experiment, participants read one of four descriptions of a professor who exhibited traits which were positive on three trait clusters and negative on one trait cluster. The four negative clusters centered around being unfair in grading, being a boring lecturer, giving excessive work and hard tests, or being cold and uncaring toward students. Participants were significantly more likely to reject the unfair professor than any of the other three. But professors displaying the other three negative characteristics did not differ significantly on likelihood of being chosen for a class. Professors who were described as "unfair" were rated significantly lower than the other three professors on "respect for the professor," "liking the professor," and "fairness of the professor." Only on "caring for students" was the rating for the professor (described as unfair) higher than another professor, and then only higher than the professor described as "uncaring"-an obvious choice.

\section{Interactional Fairness}

In addition to distributive and procedural aspects of justice, interactional justice is an important, yet often ignored, aspect of fairness research (Bies and Moag, 1986). One of the basic principals which guides human relations is the expectation of fairness in our daily interactions with others (Blai, 1988). Bies and Moag (1986) propose that people will judge the fairness of interactions based on the degree to which the interaction is seen to involve truthfulness, respect, propriety, and justification.

Other concepts of interactional justice are also important in the college classroom. Educators often stress the importance of treating students with respect as persons (Joh, 1975; Mour, 1977), but heretofore knowledge has been limited concerning student perceptions of fair practices between students and faculty members. We do know that students list "sarcasm and putdowns" more frequently than any other misbehavior they dislike in instructors (Kearney, Plax, Hays, \& Ivey, 1991). 


\section{Methodology}

This study used a descriptive questionnaire developed by the researcher to assess student perceptions of fairness. Students rated the seriousness of various faculty misbehaviors. Information was collected on student ratings of their overall happiness with college, perceptions of faculty fairness, descriptions of cheating behaviors, and acts of vandalism. Demographic information collected included year in college, ethnicity, age, gender, major, number of credit hours, average number of cuts per course, and grade point average.

Participants in this study were students enrolled in psychology and education courses. Table 1 shows the numbers of participants by ethnicity, gender and age. Majors listed included all schools on campus except for Hospitality Management. However, approximately one-third of the participants were psychology majors and one-third were education majors. The remaining participants were fairly evenly distributed among the various schools on campus.

The Statistical Package for the Social Sciences (SPSS) was employed to analyze the data, using ANOVAs, frequency, and correlational methods.

\section{Results}

\section{Fairness Correlates}

Demographic information collected included ethnicity, gender, age, year in college, major, grade point average, credit hours, and average number of classes cut during a semester. In addition, participants were asked to supply the following information on cheating and vandalism: Had they committed any behavior which might be termed as cheating; If yes, what was the behavior; Had they had ever been accused of cheating in a college environment; If yes, was the accusation justified; What was the charge; and Had they ever committed an act of vandalism on a college campus or while on a college related trip. Finally, participants rated their happiness with their college experiences, happiness with their present university, and how fair their college professors had been. 
To Improve the Academy

\begin{tabular}{|c|c|c|c|c|c|c|c|c|}
\hline \multicolumn{9}{|c|}{$\begin{array}{c}\text { TABLE } 1 \\
\text { Number of Participants by Gender, Ethnicity and Age }\end{array}$} \\
\hline \multicolumn{9}{|c|}{ Age } \\
\hline Male & $17-22$ & 23-27 & $28-34$ & $35-42$ & $43-49$ & $50>$ & Total & \\
\hline Hispanic & 13 & 7 & 3 & 1 & 2 & 0 & 26 & \\
\hline White & 17 & 7 & 3 & 1 & 0 & 0 & 28 & \\
\hline Black & 4 & 1 & 1 & 1 & 0 & 0 & 7 & \\
\hline Asian & 0 & 0 & 0 & 0 & 0 & 0 & 0 & \\
\hline Other & 1 & 2 & 0 & 0 & 0 & 0 & 3 & \\
\hline Subtotal & 35 & 17 & 7 & 3 & 2 & 0 & 64 & \multirow{3}{*}{$\begin{array}{l}\text { Total } \\
\text { Ethnic }\end{array}$} \\
\hline & \\
\hline Female & $17-22$ & 23-27 & $28-34$ & $35-42$ & $43-49$ & $50>$ & & \\
\hline Hispanic & 59 & 26 & 9 & 4 & 1 & 0 & 99 & 134 \\
\hline White & 34 & 18 & 8 & 6 & 4 & 3 & 73 & 111 \\
\hline Black & 10 & 3 & 2 & 1 & 1 & 0 & 17 & 28 \\
\hline Asian & 3 & 1 & 0 & 1 & 0 & 0 & 5 & 6 \\
\hline Other & 2 & 1 & 2 & 0 & 0 & 0 & 5 & 9 \\
\hline Subtotal & 108 & 49 & 21 & 12 & 6 & 3 & 199 & \\
\hline Missing & 6 & 2 & & & & & & 12 \\
\hline Total & 149 & 68 & 28 & 15 & 8 & 3 & 263 & 300 \\
\hline
\end{tabular}

Two of these variables, accusations of cheating and vandalism, were eliminated due to the small number of respondents. Only five participants reported ever having been accused of cheating, and only one student admitted committing an act of vandalism in college. A positive correlation was found between ratings of happiness with overall college experiences, happiness with present college experiences and perceptions regarding the fairness of professors. No significant correlation was found between fairness of professors and cheating behavior or grade point average. In comparison to younger students, older students reported professors as more fair, cut classes less, took fewer hours, were less likely to report cheating, were happier with their overall college experiences, and had higher GPAs. Students who cut more classes had lower GPAs and were more likely to cheat. 


\section{Procedural, Outcome, and Interactional Fairness}

In order to assess the relative importance of procedural, outcome, and interactional fairness to other teacher behaviors such as presenting a great lecture or giving an excessive amount of work, participants were asked to rate (on a scale of 1 to 9) the seriousness of eighteen faculty misbehaviors. Table 2 shows the mean ratings given by participants of the seriousness of misbehaviors committed by faculty. As can be seen, behaviors which violate interactional and procedural

\begin{tabular}{|l|}
\multicolumn{1}{|l|}{ TABLE 2 } \\
Participants Ratings of the Seriousness of Faculty \\
Misbehaviors
\end{tabular}


fairness expectations are rated as much more serious than being a dull, boring lecturer or giving an excessive amount of work.

Using an ANOVA, subject ratings of the seriousness of faculty misbehaviors were compared with the participants' major as the independent variable. The responses varied by major for only two faculty behaviors: "gives very dull boring lectures" and "keeps students overtime or starts class early before all students arrive." In both instances, education majors rated both behaviors significantly more serious than did psychology majors and, for the first behavior, also significantly more serious than majors in other fields. In neither case do psychology student ratings differ significantly from ratings given by students in "other" fields.

Pearson Correlation Coefficients were calculated using participant ratings of the seriousness of faculty misbehaviors and the following participant variables: age, gender, ethnicity (Hispanic and white-non-Hispanic only), year in college, grade point average, number of hours being taken, average number of cuts during a semester, cheating behavior, happiness with overall college experiences, happiness with present college, and fairness of professors. Multiple regression analyses were also calculated using these variables with the ratings of seriousness as the dependent variables. The most significant factors in participant ratings of the seriousness of faculty misbehaviors were the participants' gender and age. Females rated faculty misbehaviors as more serious than did males, especially those behaviors which relate to classroom behaviors and interactional fairness. Older students also rated faculty misbehaviors as more serious. Students who cut more classes rated faculty misbehaviors as less serious than did students who cut fewer classes.

Happiness with overall college experiences and happiness with the present college were correlated with four faculty behaviors. Multiple regression equations showed that students who were less happy with their overall college experiences rated "Unfair grading" and "Unfair tests" as more serious than did students who were happier with their college experiences. Students who were less happy with their present college saw "Giving an excessive amount of work" and "Giving busy work" as more serious than did students who were happier. 
Grade point average, cheating, and year in school were each important variables in one faculty behavior. Students with higher grade point averages saw "Unfair in grading" as more serious than those with lower GPAs; and students who reported cheating rated "Straying from the subject" as a less serious offense than did those who did not report cheating. The faculty behavior listed as least serious of all ("Is much too easy; no challenge; all students can make As") was correlated only with year in college. Upperclass students rated this behavior as much more serious than did lowerclass students.

\section{Conclusions and Recommendations for College Faculty}

This research adds to existing knowledge by exploring the relevance of equity theory to the college classroom. Earlier research has not explored the criteria for maximizing fairness in the college classroom nor the possible implications for maintaining an atmosphere of unfairness. However, this study, by analyzing student perceptions of fairness, has brought to light some of the criteria necessary for optimal student satisfaction and learning. The relationship between fairness and learning has not been directly investigated, though several related findings suggest that student perceptions of interactional or procedural unfairness in the classroom are highly correlated with, if not the cause of, not only lower student satisfaction but decreased learning as well. Studies repeatedly show correlations between instructor fairness and student achievement (Bryson, 1974; Frey, 1976; Marsh \& Overall, 1980). In addition, we might find that dropping out, underachievement, poor academic motivation, and failure are all related, at least partly, to student perceptions of interactional or procedural unfairness.

Previous studies have emphasized the importance of considerations of equity in grading policies (Rodabaugh \& Kravitz, 1994) and the importance of procedural fairness in testing procedures and setting classroom policies (Rodabaugh \& Kravitz, in press). In addition, the present study emphasizes the importance of not only procedural fairness in the classroom but also the need for interactional fairness. Faculty members who wish to optimize college student learning and satisfaction should keep the following research findings in mind. 
1. Student perceptions of fairness among their professors is correlated with ratings of happiness with college.

2. Student happiness with college is correlated with grade point averages.

3. The most serious offense a faculty member can commit is to show partiality toward some students. In addition, students also consider other interactional offenses to be very serious: being angry or mean, and embarrassing students in class.

4. Procedural offenses which are perceived to be especially serious include being unfair in grading and using unfair tests.

5. Even though older students are especially sensitive to unfairness by faculty, they still rate professors as being more fair, and they are happier with college than younger students.

6. Females are more sensitive to faculty misbehaviors and see unfairness as a more serious matter than do males.

Faculty members should remember that college students are more concerned with fairness in the classroom than with easy grades or brilliant lectures. Students do not object to strict rules as long as the rules are fair and administered equally. Students will even accept excessive work and difficult tests if faculty members are fair. If a college faculty member creates an atmosphere of fairness and impartiality, students will usually respond with respect and, if given the opportunity, select that faculty member for a class.

\section{References}

Adams, J. S. (1965). Inequity in social exchange. In L. Berkowitz (Ed.), Advances in experimental social psychology, (Vol. 2, pp. 267-299). New York: Academic.

Benton, A. A. (1971). Productivity, distributive justice and bargaining among children. Journal of Personality and Social Psychology, 18, 68-78.

Bies, R. J. \& Moag, J. S. (1986). Interactional justice: Communication criteria of fairness. In R. J. Lewicki, B. H. Sheppard, \& M. H. Bazerman (Eds.), Research on negotiation in organizations, (Vol. 1, pp. 43-55). Greenwich, CT: JAI Press.

Blai, B., Jr. (1988). The human in human relations: Some comments. Psychology-A Journal of Human Behavior, 25, 93-97.

Boldizar, J. P., Perry, D. G., \& Perry, L. C. (1988). Gender and reward distributions: A test of two hypotheses. Sex Roles, 19, 569-579.

Bryson, R. (1974). Teacher evaluations and student learning: A reexamination. Journal of Educational Research, 68, 12-14. 
DeMore, S. W., Fisher, J. D., \& Baron, R. M. (1988). The equity-control model as a predictor of vandalism among college students. Journal of Applied Social Psychology, 18, 80-91.

Deutsch, M. (1975). Equity, equality, and need: What determines which value will be used as the basis of distributive justice? Journal of Social Issues, 31, 137-149.

Feldman, K. A. (1976). The superior college teacher from the students' view. Research in Higher Education, 5, 243-288.

Folger, R., Rosenfield, D., Grove, J., \& Cochran, L. (1979). Effects of "voice" and peer opinions on responses to inequity. Journal of Personality and Social Psychology, 37, 2253-2261.

Frey, P. W. (1976). Validity of student instructional ratings: Does timing matter? Journal of Higher Education, 47, 327-336.

Joh, J. N. (1975). Respect for persons. Theory into Practice, 14, 271-278.

Kearney, P., Plax, T. G., Hays, E. R., \& Ivey, M. J. (1991). College teacher misbehaviors: What students don't like about what teachers say and do. Communication Quarterly, 39, 309-324.

Leventhal, G. S. (1976). Fairness in social relationships. In J. Thibaut, J. Spence, \& R. Carson (Eds.), Contemporary issues in social psychology (pp. 211-239). Morristown, NJ: General Learning Press.

Leventhal, G. S. (1980). What should be done with equity theory? New approaches to the study of fairness in social relations. In K. J. Gergen, M. S. Greenberg, \& R. H. Willis (Eds.), Social exchange: Advances in theory and research, (pp. 27-55). New York: Plenum.

Marsh, H. W., \& Overall, J. U. (1980). Validity of students' evaluations of teaching effectiveness: Cognitive and affective criteria. Journal of Educational Psychology, $72,468-475$.

Meredith, G. M. (1983). Diagnostic value of composite student-based ratings of instruction. Psychological Reports, 52, 549-550.

Mour, S. I. (1977). Teacher behaviors and ecological balance. Behavioral Disorders, 3, 55-58.

Murphy-Berman, V., Berman, J. J., Singh, P., Pachauri, A., \& Kumar, P. (1984).Factors affecting allocation to needy and meritorious recipients: A cross-cultural comparison. Journal of Personality and Social Psychology, 46, 1267-1272.

Odom, C. L. (1943). An objective determination of the qualities of a good college teacher. Peabody Journal of Education, 21, 109-116.

Rodabaugh, R. C. \& Kravitz, D. A. (1994). College students reactions to equity-, equality-, and need-based grading procedures. Manuscript submitted for publication.

Rodabaugh, R. C. \& Kravitz, D. A. (in press). Effects of procedural fairness on student judgements of professors. Journal on Excellence in College Teaching.

Shaw, E. L., Jr., Partridge, M. E., \& Gorrell, J. (1990). Worlds apart, good teaching is the same. Georgia Social Science Journal, 21, 1-8. 
Thibaut, J., \& Walker, L. (1978). A theory of procedure. California Law Review, 66, 541-566. 